\title{
Heinz Heinemann. The Berkeley Years (1978-1993)
}

\author{
Gabor A. Somorjai
}

Received: 27 August 2009/Accepted: 27 August 2009/Published online: 23 September 2009

(C) The Author(s) 2009. This article is published with open access at Springerlink.com

\begin{abstract}
Heinz Heineman came to Berkeley in 1978 and stayed there for 15 years. This was the time of the energy crisis and we did not have anybody like him who had such a tremendous industrial experience with oil and coal conversion technology and science. He was interested in the conversion of coal to gaseous molecules and our studies with model catalysts appealed to him and attracted him. In a way, Heinz Heineman was bigger than life, since he played such a seminal role in the history of American catalysis science.
\end{abstract}

Keywords Heinemann · Catalysis

\section{Introduction}

Catalysis sciences dates back to the 1930s with Vladimir Ipatieff, Herman Pines, Eugene Houdry, Paul Emmett, Keith Hall and Hugh Taylor, who had established the fundamental phenomena by focusing on motor fuel production by catalytic means, the $\mathrm{CO}$ hydrogenation reactions, ammonia synthesis and some of the fundamental phenomena that led to the definition of active sites in heterogeneous catalysis. This period was followed by the industrial might of the petroleum industry, Vladimir Haensel of Universal Oil Products Co, Jules Rabo of Union

G. A. Somorjai $(\bowtie)$

Department of Chemistry, University of California, Berkeley, CA 94720, USA

e-mail: somorjai@berkeley.edu

G. A. Somorjai

Materials Sciences Division and Chemical Sciences Division, Lawrence Berkeley National Laboratory, Berkeley, CA 94720, USA
Carbide, Otto Beeck at Shell, Paul Weiss at Mobile, John Sinfelt at Exxon, Tom Hughes at Chevron, and others, who focused on catalytic conversion of fuels to high-octane gasoline and diesel fuels. The presence of a Dutch component in American catalysis science was caused by the relocation of much of Shell's research from the Netherlands because of the German occupation, to the United States.

\section{Catalytic Research of Heinemann in Berkeley}

Heinemann (Fig. 1) was an industrial scientist in this very period. After a long period of industrial research with Kellogg he moved to Mobil and retired from the company just before coming to Berkeley. During this period, catalysis science performed so excellently in industry declined and the field moved to centers in academia, and Berkeley was one of them. He employed and worked with 12 postdoctoral fellows over a 15 year period who are maintaining their activity even at present.

He started to work with graphite as a model carbon solid to study the catalytic gasification using potassium hydroxide as a catalyst $[1,2]$. He found at relatively low temperature at $800 \mathrm{~K}$ hydrocarbons from $\mathrm{C}_{1}$ to $\mathrm{C}_{6}$ could be formed with high efficiency as shown in Fig. 2. He worked on the mechanism and found that the carbon bond next to the $\mathrm{OH}$ bond of potassium hydroxide had to be broken as the rate limiting step to produce products of $\mathrm{CO}$ and hydrocarbons.

He found other catalysts also worked for carbon gasification at $900 \mathrm{~K}$ using mixtures of potassium hydroxide and oxides of transition metals as catalysts [3]. Out of these transition metal mixtures, iron oxide and nickel oxide were the most efficient and had the highest activity. Electron 


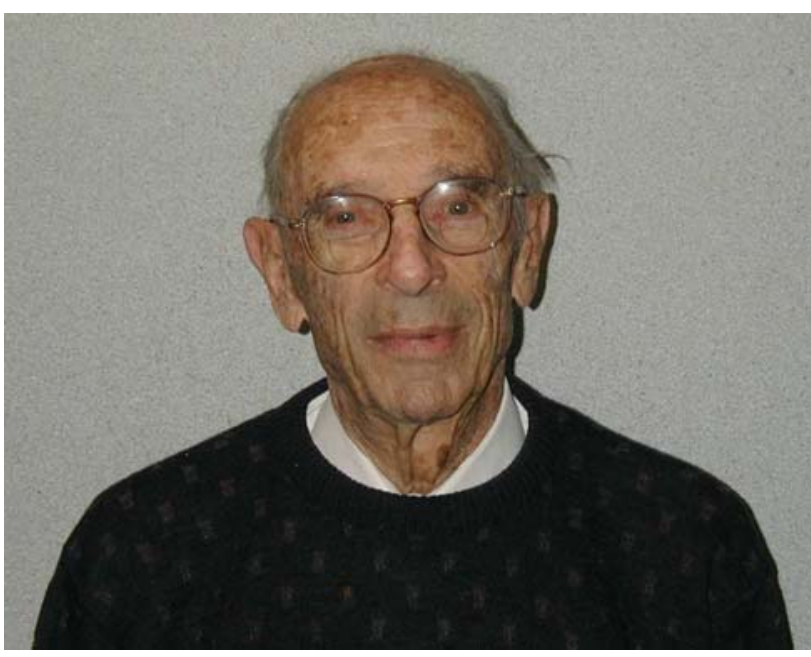

Fig. 1 Heinz Heinemann

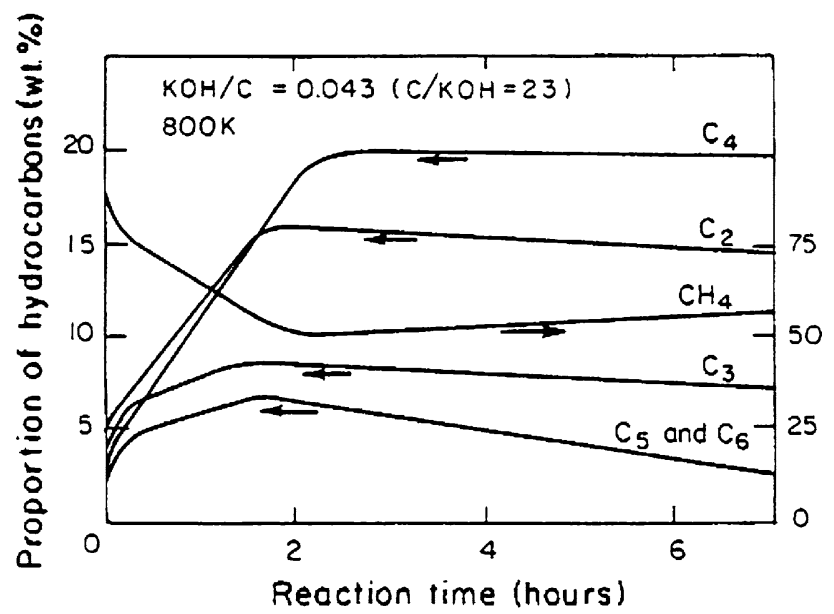

Fig. 2 Plot of dependence on reaction time of the proportion of hydrocarbons for a $\mathrm{KOH} / \mathrm{C}$ loading equal to 0.043 (mol)

microscopy studies revealed that potassium hydroxide alone as a catalyst channeled into the graphite and at the end of the channel the potassium hydroxide dissolved the carbon, which then gasified. When a transition metal was used, both edge recession and channeling into the graphite was observable. Following the work with graphite as a model catalyst the steam gasification with chars was studied at temperatures below $1,000 \mathrm{~K}$ using a potassium oxide-calcium oxide catalyst, which shows superior resistance to deactivation by sulfur $[4,5]$.

Heinz Heinemann in the 1989-1990 period turned then to the conversion of methane by oxydehydrogenation using catalysts such a calcium, nickel or potassium oxides at low temperatures, below $600{ }^{\circ} \mathrm{C}$ [5]. We found catalytic oxidative coupling of methane to produce $\mathrm{C}_{3}$ and $\mathrm{C}_{4}$ paraffins and olefins under these circumstances. Oxydehydrogenation was the focus of his work for these remaining years in Berkeley [6-10]. He pursued that with mechanistic studies using oxygen isotopes to study isotope exchange to reveal the mechanism of oxydehydrogenation and utilized other catalysts such as ZSM-5 zeolites and magnesium lithium oxide catalysts, and the effect of steam [10].

Heinz Heinemann left with us a tradition of curiosity, the interest in technology and energy conversion, close scrutiny of experimental data and carrying out seminal studies of kinetics and catalyst structures to understand the fundamental ingredients of catalyst activity and selectivity. He had important influence on the next generation of researchers and he played a significant role in the history of catalysis science.

Acknowledgments This work was supported by the Director, Office of Science, Office of Advanced Scientific Computing Research, Office of Basic Energy Sciences, Materials Sciences and Engineering Division, Chemical Sciences, Geosciences, and Biosciences Division, of the US Department of Energy under Contract No. DE-AC02$05 \mathrm{CH} 11231$.

Open Access This article is distributed under the terms of the Creative Commons Attribution Noncommercial License which permits any noncommercial use, distribution, and reproduction in any medium, provided the original author(s) and source are credited.

\section{References}

1. Delannay F, Tysoe WT, Heinemann H, Somorjai GA (1984) Carbon 22:401-407

2. Delannay F, Tysoe WT, Heinemann H, Somorjai GA (1984) Appl Catal 10:111-123

3. Carrazza J, Tysoe WT, Heinemann H, Somorjai GA (1985) J Catal 96:234-241

4. Pereira P, Csencsits R, Somorjai GA, Heinemann H (1990) J Catal 123:463-476

5. Pereira P, Lee SH, Somorjai GA, Heinemann H (1990) Catal Lett 6:255-262

6. Rasko J, Somorjai GA, Heinemann H (1992) Appl Catal A Gen 84:57-75

7. Chang YF, Somorjai GA, Heinemann H (1993) J Catal 142:697-707

8. Chang YF, Somorjai GA, Heinemann H (1993) J Catal 141:713-720

9. Chang YF, Somorjai GA, Heinemann H (1993) Appl Catal A Gen 96:305-318

10. Chang YF, Somorjai GA, Heinemann H (1995) J Catal 154:24-32 